\title{
The Effects of Endocrine Disrupting Chemicals on Biomarkers of Inflammation Produced by Lipopolysaccharide Stimulated RAW264.7 Macrophages
}

\author{
Vedastus W. Makene * and Edmund J. Pool \\ Department of Medical Bioscience, University of the Western Cape, Bellville 7535, South Africa \\ * Correspondence: vmakene@gmail.com; Tel.: +27-21-959-3535; Fax: +27-21-959-3125
}

Received: 19 May 2019; Accepted: 26 July 2019; Published: 14 August 2019

\begin{abstract}
Endocrine disrupting chemicals (EDCs) are common pollutants in the environment and can induce disruption of the endocrine and immune systems. The present study evaluated the effects of selected common environmental EDCs on secretion of inflammatory biomarkers by RAW264.7 cells. The EDCs investigated were Estradiol (E2), $5 \alpha$-dihydrotestosterone (DHT), and Bisphenol A (BPA). To evaluate if the effects caused by EDCs were modulated by steroid hormone receptors, antagonists of estrogen and androgen receptors were used. The steroid receptor antagonists used were Tamoxifen, an estrogen receptor antagonist, and Flutamide, an androgen receptor antagonist. Secretion of biomarkers of inflammation, namely nitric oxide $(\mathrm{NO})$ and interleukin 6 (IL-6), were monitored. The NO was determined using Griess reaction and IL-6 was measured by enzyme linked immunosorbent assay (ELISA). Although $5 \mu \mathrm{g} / \mathrm{mL}$ E2, DHT, and BPA were not toxic to RAW264.7 cell cultures, the same treatments significantly $(p<0.001)$ reduced both NO and IL-6 secretion by lipopolysaccharide (LPS)-stimulated RAW264.7 cell cultures. The suppression of NO and IL-6 secretion indicate inhibition of inflammation by DHT, E2, and BPA. The inhibitory effects of DHT, E2 and BPA are partially mediated via their cellular receptors, because the effects were reversed by their respective receptor antagonists. Flutamide reversed the effects of DHT, while Tamoxifen reversed the effects of E2 and BPA. In conclusion, E2, BPA, and DHT inhibit the synthesis of inflammation biomarkers by LPS-stimulated RAW264.7 cells. The inhibitory effects of EDCs can be partially reversed by the addition of an estrogen receptor antagonist for E2 and BPA, and an androgenic receptor antagonist for DHT. The inhibition of inflammatory response in stimulated RAW264.7 cells may be a useful bioassay model for monitoring estrogenic and androgenic pollutants.
\end{abstract}

Keywords: Estradiol; $5 \alpha$-dihydrotestosterone; Bisphenol A; anti-inflammatory; nitric oxide; interleukin 6

\section{Introduction}

Endocrine disrupting chemicals (EDCs) are environmental compounds that can interfere with biosynthesis, secretion, action, or metabolism of endogenous hormones, resulting in altered normal hormone actions [1,2]. They include compounds such as industrial chemicals, agricultural chemicals like pesticides, natural and synthetic hormones, and pharmaceuticals. These chemicals are widely distributed in the environment and especially in wastewater. Common examples reported in the environment are estrogenic steroids like Estradiol (E2) and Bisphenol A (BPA) [3,4] and androgenic steroids like testosterone and $5 \alpha$-dihydrotestosterone (DHT) $[5,6]$. While BPA is an industrial chemical with many applications, testosterone and E2 are natural hormones of male and female animals, respectively. 
Both estrogenic and androgenic chemicals are common pollutants in municipal wastewater. They are persistent in the environment and, in most cases, are resistant to removal by common conversional wastewater treatment techniques. Therefore, some of these pollutants can pass through wastewater treatment plants (WWTPs) and contaminate the environment. For example, Liu et al. [6] reported the presence of estrogenic E2 among several steroids in the environment after analysis of sludge and surface water samples. In another study, Sun et al. [3] reported some E2 and BPA activities in both sewage and reclaimed water.

Similar to estrogenic EDCs, androgenic steroids are also common in sewage and surface water bodies. Bell et al. [5] reported high androgenic activities in sewage samples. Along with other androgenic hormones, $5 \alpha$-dihydrotestosterone (DHT) has also been reported in sewage [6]. DHT is a more biologically active form of testosterone. It is a derivative of testosterone synthesized from testosterone by enzymatic action of 5-reductase $[7,8]$.

Exposure to environmental estrogenic and androgenic compounds causes many adverse health effects on the endocrine system, leading to several disorders in humans and animals $[1,2,9,10]$. The most common reported effects are reproductive disorders, including reproductive anomalies, sexual dysfunctions, and cancers of reproductive origin [11]. Apart from disruption of reproductive structure and functions, estrogenic and androgenic compounds are also known to induce immunotoxicity [12]. They induce immunotoxicity by interfering with activation and survival of immune cells; and alteration of cytokines and synthesis of inflammatory mediators [9]. The altered immune response is normally characterized by either suppression of immunity or stimulation of immune response. The immune suppression is normally characterized by enhanced disease susceptibility and inability to eliminate cancer cells $[13,14]$. On the other hand, the overstimulation of the immune system is characterized by immune hypersensitivity [15].

The inflammatory reaction is an important immunological response, which is induced by many inflammatory factors. These inflammatory factors include pathogens, injury, organic compounds, toxins, and endotoxins like lipopolysaccharide (LPS) [16]. The resulting inflammatory responses involve many immune cells. One of these types of cells is macrophages, which are phagocytic cells derived from circulating monocytes. They form the first line of the innate part of the immune system. When macrophages are stimulated, they ingest and digest invading pathogens, dead cells, and any other foreign substances [17]. Therefore, macrophage stimulation is one of the early immune responses to infection. For example, exposure of macrophages to LPS, a gram negative bacteria membrane component, induces an inflammatory response. The induction of an inflammatory response by LPS is through activation of a Toll-like receptor (TLR-4), which is expressed on the cell surface of macrophages $[17,18]$.

Estrogenic and androgenic compounds can also induce an immune response in macrophages through their specific receptors, namely, estrogen receptors (ERs) and androgen receptors (ARs), respectively $[19,20]$. Both ERs and ARs are members of the nuclear receptor family of ligand-dependent transcription factors [21]. Therefore, exposure of macrophages to estrogenic and androgenic compounds may activate or inhibit expression of nuclear factor kappa B (NFKB), which leads to alteration of inflammatory mediators and cytokine secretion [18]. Inhibition of an inflammatory response induced by estrogen has been reported in wound healing [22]. On the other hand, suppression effects of testosterone on inflammation have been associated with many metabolic diseases [23]. In fact, recently, there is evidence in literature showing that a low testosterone level correlates with occurrence of metabolic diseases, characterized by increased expression of biomarkers of inflammation [24].

Activated macrophages initiate inflammatory responses by inducing secretion of many inflammatory mediators and pro-inflammatory cytokines [25]. Examples of common inflammatory mediators and pro-inflammatory cytokines secreted by macrophages are nitric oxide (NO) and interleukin 6 (IL-6), respectively [26]. IL-6 is a pro-inflammatory cytokine with many functions, including supporting chronic inflammatory reaction, induction of acute phase reactions, and inducible nitric oxide synthase (iNOS) $[26,27]$. Inducible nitric oxide synthase (iNOS) is a key enzyme in NO 
production. NO is a small molecule secreted by many tissue cells including macrophages. Therefore, secretion of both NO and IL-6 in macrophages is extensively used as a biomarker of inflammation studies [28-30].

Inflammatory responses have been studied in vitro using established cell lines like mouse RAW264.7 macrophages. This cell line was developed from mouse ascites leukemia cells. When RAW264.7 cells are stimulated, they secrete inflammatory mediators like NO and IL-6. Stimulation of RAW264.7 cells with LPS has been used extensively to study the immunomodulating effects of natural products and herbs [31-34]. However, there are relatively very few reports on the use of RAW264.7 cells to study anti-inflammatory effects of common pollutants like DHT, E2, and BPA. The present study was done to evaluate the in vitro effects of common EDCs, such as DHT, E2, and BPA, on cytotoxicity and inflammatory biomarker secretion by LPS-stimulated RAW264.7 macrophages. This study also evaluated whether effects of the EDCs on inflammatory biomarkers are mediated via their respective steroid receptors.

\section{Material and Methods}

\subsection{Reagents}

Lipopolysaccharides (LPS) from Escherichia coli 0111:B4, Dimethyl sulfoxide (DMSO), $5 \alpha$-dihydrotestosterone (DHT), Estradiol $\left(\mathrm{E}_{2}\right)$, Bisphenol A (BPA), Flutamide, and Tamoxifen were purchased from Sigma-Aldrich Chemie Gmbh, Munich, Germany. The LPS, DHT, E2, BPA, flutamide, and tamoxifen were dissolved in DMSO (Sigma-Aldrich, Germany).

\subsection{Cells Culture}

A mouse macrophage RAW264.7 cell line, purchased from American Type Culture Collection (ATCC TIB-71, Manassas, VA, USA), was used in this study. The RAW264.7 cells were cultured in Dulbecco's Modified Eagle's medium (DMEM, Lonza, Cape Town, South Africa), supplemented with $10 \%$ heat inactivated fetal bovine serum (FBS), $1 \% v / v$ antibiotic/antimycotic mixture (Sigma-Aldrich), $0.5 \%$ v/v gentamycin (Sigma-Aldrich), and 1\% v/v glutamax (Gibco, Life Technology, Carlsbad, CA, USA). The cells were cultured in 96-well plates at a density of $5 \times 10^{5}$ cells $/ \mathrm{mL}$ in a humidified incubator at $37^{\circ} \mathrm{C}$ and $5 \% \mathrm{CO}_{2}$ until confluent. At confluence, cells were treated as follows: Normal medium for negative control and medium supplemented with $1 \mu \mathrm{g} / \mathrm{mL}$ lipopolysaccharides (LPS) from Escherichia coli 0111:B4 (Sigma-Aldrich, Germany) as a positive control. Some cell cultures stimulated with LPS $(1 \mu \mathrm{g} / \mathrm{mL})$ were treated with $5 \mu \mathrm{g} / \mathrm{mL}$ of each of DHT, E2, and BPA alone or in combination with $2 \mu \mathrm{g} / \mathrm{mL}$ of flutamide or tamoxifen. The optimal concentration of compounds was determined by serial dilution (data not shown). The dilution of DHT, E2, and BPA started with 1 in $100 \mathrm{of} 10 \mu \mathrm{g} / \mathrm{mL}$ of compound. The concentrations of EDCs starting from 1 in $200(5 \mu \mathrm{g} / \mathrm{mL})$ and further dilutions did not affect cell viability and were not different from the control. Optimal concentrations of flutamide and tamoxifen treatment were also determined by serial dilution, starting from 1 in 500 dilutions of $5 \mu \mathrm{g} / \mathrm{mL}$ of each. The concentrations of flutamide and tamoxifen, starting from 1 in $1000(2.5 \mu \mathrm{g} / \mathrm{mL})$, and further dilutions alone had no suppression effects on cell viability, NO, and IL-6 secretion in RAW264.7 cells. The cells were cultured in medium supplemented with LPS $(1 \mu \mathrm{g} / \mathrm{mL})$ overnight. Then, cell cultures stimulated with LPS were treated with $5 \mu \mathrm{g} / \mathrm{mL}$ of each of DHT, E2, and BPA alone or in combination with $2 \mu \mathrm{g} / \mathrm{mL}$ of flutamide or tamoxifen and incubated at $37^{\circ} \mathrm{C}$ and $5 \% \mathrm{CO}_{2}$ overnight. After overnight incubation at $37^{\circ} \mathrm{C}$ and $5 \% \mathrm{CO}_{2}$, culture supernatants were collected for NO and IL-6 assays. The cells remaining on the plate were used for cell viability assays. Each assay was carried in four replicates.

\subsection{Cell Viability}

The cell viability was determined using the chromogenic WST-1 assay. The assay is based on the breakdown of the water-soluble (2-(4-Iodophenyl)-3-(4-nitrophenyl)-5-(2,4-disulfophenyl)$2 \mathrm{H}$-tetrazolium by the dehydrogenase enzyme to produce water-soluble formazan dye that can be 
monitored spectrophotometrically. In brief, the assay procedure was as follows: After removal of cell supernatant from culture, each plate well received $100 \mu \mathrm{L}$ of medium supplemented with $10 \%$ WST-1 reagent (Roche, Basel, Switzerland). The absorbance was read immediately after addition of WST-1 medium and a second reading was done after incubation for $30 \mathrm{~min}$ at $37^{\circ} \mathrm{C}$ and $5 \% \mathrm{CO}_{2}$. The change in absorbance at $450 \mathrm{~nm}$ over $30 \mathrm{~min}$ was used as a measure of cell viability.

\subsection{Nitric Oxide Determination}

Nitric oxide (NO) secreted by cells into the cell culture was determined using the Griess reaction. Cell culture supernatant in 96-well plates (Nunc, Roskilde, Denmark) was mixed with an equal volume of Griess reagent made up of $1 \% \mathrm{~m} / \mathrm{v}$ sulphanilamide (Sigma-Aldrich, Germany), $0.01 \% \mathrm{~m} / \mathrm{v}$ naphthyl ethylenediamine dihydrochloride (Sigma-Aldrich), and $2.5 \%$ phosphoric acid. The mixture was allowed to react for $15 \mathrm{~min}$ at room temperature. The colour developed was measured at $540 \mathrm{~nm}$ using a microplate reader (Multiskan Ex, Thermo Electron Corporation). The concentration of NO was determined from a standard curve generated using 1.56-100 $\mu \mathrm{M}$ sodium nitrite (Sigma-Aldrich, Germany).

\subsection{Interleukin-6 Determination}

Interleukin 6 (IL-6) in culture supernatant was determined using a double antibody sandwich enzyme linked assay (DAS ELISA), with a commercial kit (e-Bioscience, Ready-Set-Go, Waltham, MA, USA). The assays were done on Nunc Maxisorp 96-well plates (Nunc, Denmark). The ELISA kit contains all reagents required for the assay and the manufacturers' assay protocol was followed. In brief, the protocol involved coating the ELISA plate with capture antibody, anti-mouse IL-6 diluted in coating buffer (PBS), and incubated overnight at $37^{\circ} \mathrm{C}$. Then, the plate was washed five times in wash buffer made of PBS with $0.1 \% v / v$ Tween. After washing, the plate was blocked with assay diluent for $1 \mathrm{~h}$ at room temperature. After another five washes, IL-6 standard and cell culture supernatant were added to each well accordingly and incubated for two hours at room temperature. The plate was washed again five times, then detection antibody, biotinylated anti-mouse IL-6, was added to each well and incubated for $1 \mathrm{~h}$ at room temperature. After another wash, Avidin-horse radish peroxidise (HRP) conjugate-was added and incubated for $30 \mathrm{~min}$ at room temperature. The plate was washed seven times, then TMB substrate was added and incubated in the dark for $15 \mathrm{~min}$ at room temperature. The reaction was stopped with $0.5 \mathrm{M} \mathrm{H}_{2} \mathrm{SO}_{4}$ stop solution, and the absorbance was read at $450 \mathrm{~nm}$ with a multiskan microplate reader (Multiskan Ex, Thermo Electron Corporation).

\subsection{Statistical Analysis}

The data are presented as mean $\pm \mathrm{SD}(n=4)$, which were statistically analyzed with one way variance analysis (ANOVA) using sigmastat (SigmaStat software, Inc., CA, USA). The results of cell viability are presented as a percentage of the negative control. The mean values of NO and IL- 6 concentration for each treatment were compared with the positive control. $p$-value $<0.001$ was considered statistically significant.

\section{Results}

\subsection{Effects of Selected EDCs on Cell Viability}

The effects of DHT, E2, and BPA alone and in combination with flutamide or tamoxifen on viability of stimulated RAW264.7 cells are shown in Figure 1. The cell viability is presented as a percentage of the negative control. None of the treatments reduce RAW264.7 cell viability as compared with the positive control treated with LPS $(1 \mu \mathrm{g} / \mathrm{mL})$. 


\section{WST-1}

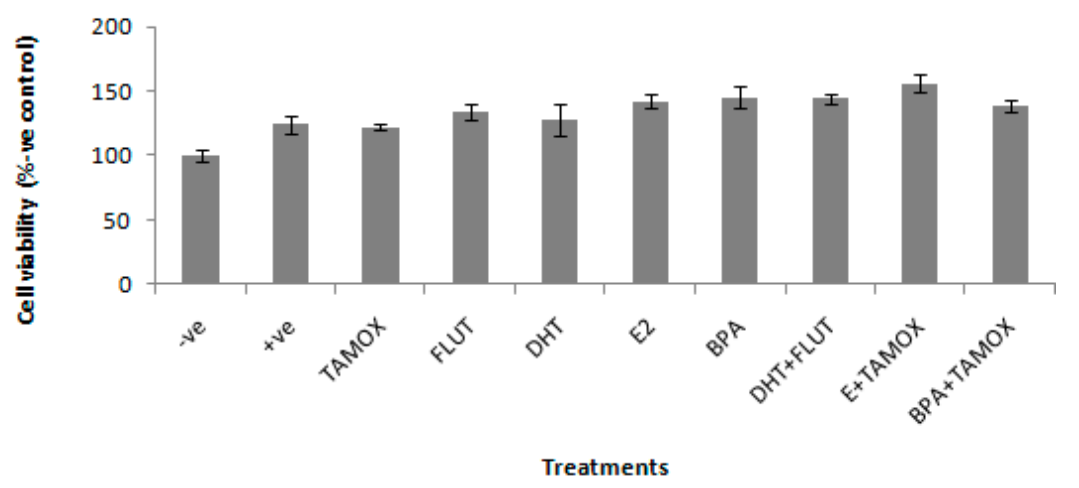

Figure 1. Effects of 5 $\alpha$-dihydrotestosterone (DHT), Estradiol (E2), and Bisphenol A (BPA) alone and in combination with flutamide or tamoxifen on viability of RAW264.7 cells, stimulated with $1 \mu \mathrm{g} / \mathrm{mL}$ lipopolysaccharide (LPS). The stimulated cells were treated with $5 \mu \mathrm{g} / \mathrm{mL}$ of DHT, E2, or BPA; and flutamide (FLUT) or tamoxifen (TAMOX) at $2 \mu \mathrm{g} / \mathrm{mL}$; negative control was treated with normal medium and positive control was treated with LPS $(1 \mu \mathrm{g} / \mathrm{mL})$. The results of cell viability are presented as percentage of negative control.

\subsection{Effects of Selected EDCs on NO Production}

The effects of DHT, E2, and BPA alone and in combination with flutamide or tamoxifen on NO production in stimulated RAW264.7 cells were determined by NO assay in cell culture supernatant. The results of the effects of DHT, E2, and BPA alone and in combination with flutamide or tamoxifen on NO secretion in RAW264.7 cells stimulated with $1 \mu \mathrm{g} / \mathrm{mL}$ LPS are shown in Figure 2.

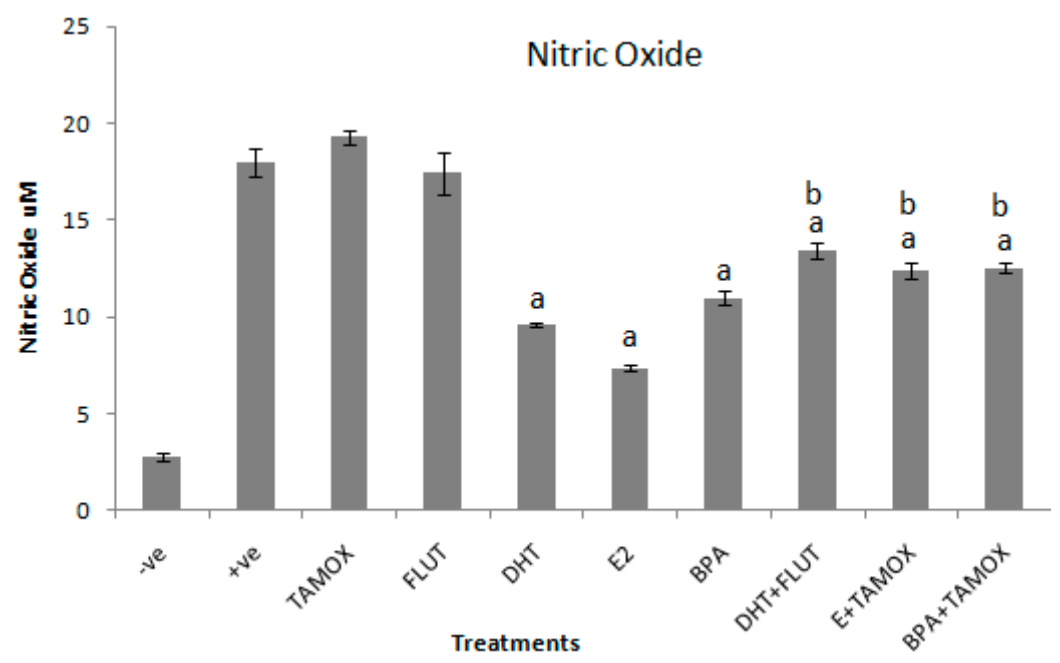

Figure 2. Effects of DHT, E2, and BPA alone and in combination with tamoxifen (TAMOX) or flutamide (FLUT) on secretion of nitric oxide (NO) in supernatant of RAW264.7 cells stimulated with $1 \mu \mathrm{g} / \mathrm{mL}$ LPS. The stimulated cells were treated with $5 \mu \mathrm{g} / \mathrm{mL}$ of DHT, E2, and BPA alone and $2 \mu \mathrm{g} / \mathrm{mL}$ of flutamide or tamoxifen. Negative control was treated with normal medium and positive control treated with LPS $(1 \mu \mathrm{g} / \mathrm{mL})$. The results are presented as mean \pm SD; a-indicates that NO level is significantly $(p<0.001)$ lower than the positive control; $\mathbf{b}$-indicates that NO level is significantly $(p<0.001)$ higher than levels of NO secreted by cells treated with DHT, E2, and BPA alone.

The results reveal that exposure of the stimulated cells to tamoxifen or flutamide alone had no significant effect on $\mathrm{NO}$ secretion. Exposure of the stimulated culture cells to $5 \mu \mathrm{g} / \mathrm{mL}$ of DHT, E2, and BPA significantly $(p<0.001)$ decreased NO secretion when compared to the positive control. The strongest suppression effect was induced by E2 $(7.4 \pm 0.13 \mu \mathrm{M})$. Next to E2 was DHT 
$(9.6 \pm 0.13 \mu \mathrm{M})$ and relatively weak suppression of NO production was induced by BPA $(10.9 \pm 0.4 \mu \mathrm{M})$. The inhibitory effects of EDCs were reversed by the addition of their respective antagonist compounds. Addition of flutamide, a chemical with anti-androgenic effects, significantly $(p<0.001)$ reversed the anti-inflammatory effects of DHT. The NO production induced by DHT alone was $9.6 \pm 0.13 \mu \mathrm{M}$, whereas DHT in combination with flutamide induced $13.4 \pm 0.13 \mu \mathrm{M}$ of NO. Similarly, addition of tamoxifen, a chemical with anti-estrogenic effects, significantly $(p<0.001)$ reversed the effects of both estradiol and BPA. E2 alone induced $7.4 \pm 0.13 \mu \mathrm{M}$, while E2 in combination with tamoxifen increased NO production to $12.4 \pm 0.42 \mu \mathrm{M}$. BPA alone induced $10.9 \pm 0.4 \mu \mathrm{M}$ of NO. BPA in combination with tamoxifen induced $12.5 \pm 0.28 \mu \mathrm{M}$ of $\mathrm{NO}$.

\subsection{Effects of Selected EDCs on IL-6 Secretion}

The effects of DHT, E2, and BPA alone and in combination with flutamide or tamoxifen on secretion of IL-6 in stimulated RAW264.7 cells was determined in cell culture supernatant, using a double antibody sandwich enzyme linked assay (DAS ELISA). The effects of DHT, E2, and BPA alone and in combination with flutamide or tamoxifen on secretion of IL-6 in stimulated RAW264.7 cells are shown in Figure 3. The results show that exposure of cells to DHT, E2, and BPA alone significantly $(p<0.001)$ reduced the IL-6 response in stimulated RAW264.7 cells.

IL-6

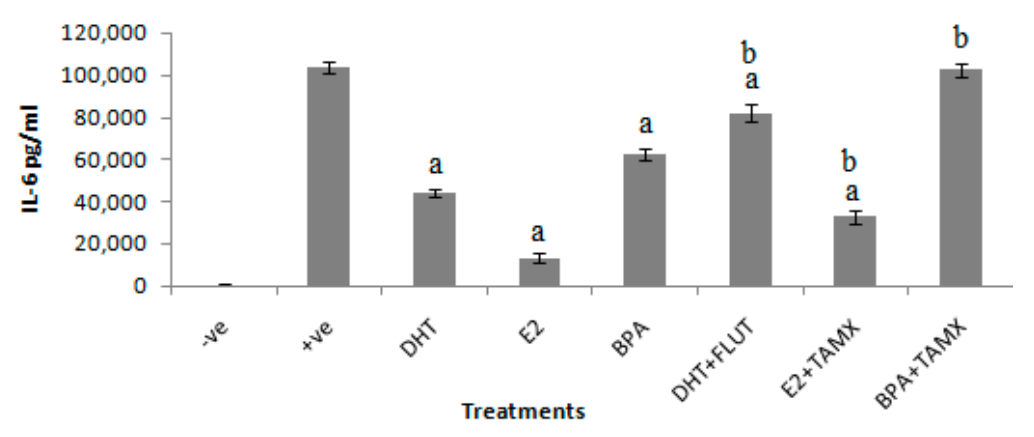

Figure 3. Effects of DHT, E2, and BPA alone and in combination with flutamide or tamoxifen on IL-6 secretion in RAW264.7 cells stimulated with $1 \mu \mathrm{g} / \mathrm{mL}$ LPS. The stimulated cells were treated with $5 \mu \mathrm{g} / \mathrm{mL}$ of DHT, E2, and BPA and $2 \mu \mathrm{g} / \mathrm{mL}$ of flutamide (FLUT) or tamoxifen (TAMOX). Negative control was treated with normal medium and positive was control-treated with LPS $(1 \mu \mathrm{g} / \mathrm{mL})$. The results are presented as mean $\pm \mathrm{SD}$; a-indicates that IL-6 level is significantly $(p<0.001)$ lower than the positive control; $\mathbf{b}$-indicates that IL-6 level is significantly $(p<0.001)$ higher than levels of IL-6 secreted by cells treated with DHT, E2, and BPA alone.

The results show that the positive control treated with LPS $(1 \mu \mathrm{g} / \mathrm{mL})$ secreted IL- 6 as high as $103,914 \pm 2620 \mathrm{pg} / \mathrm{mL}$. Addition of DHT alone to stimulated cultures suppressed IL-6 secretion to $43,943 \pm 1750 \mathrm{pg} / \mathrm{mL}$. DHT in combination with flutamide secreted 81,871 $\pm 4098 \mathrm{pg} / \mathrm{mL}$ of IL-6. The highest IL-6 suppression effect was evident in cells treated with E2. Treatment of stimulated RAW264.7 cell culture with E2 suppressed IL-6 to 13,329 $\pm 1971 \mathrm{pg} / \mathrm{mL}$. Tamoxifen or flutamide alone had no suppression effect on IL-6 secretion in stimulated RAW264.7 cell culture (data not shown). Addition of tamoxifen with an antagonistic effect significantly reversed the anti-inflammatory effects of E2. The combination of E2 and tamoxifen secreted 32,871 $\pm 3093 \mathrm{pg} / \mathrm{mL}$ of IL-6. A relatively low suppression effect on IL-6 secretion was induced by BPA treatment. BPA alone induced 62,671 \pm 2903 $\mathrm{pg} / \mathrm{mL}$ of IL-6, which was reversed when combined with tamoxifen to $102,529 \pm 3235 \mathrm{pg} / \mathrm{mL}$ of IL-6.

\section{Discussion}

Pollutants with estrogenic and androgenic effects are common in wastewater treatment facilities and receiving water bodies $[4,35]$. As a result, there have been increasing concerns over their association with several adverse effects to the environment, animals, and humans [3]. The most common 
adverse health effect reported is endocrine disruption, especially reproductive system modulation [36]. Apart from the disruption of the reproductive system, an increasing number of reports suggest that androgenic and estrogenic compounds can also cause immune disruption. The disruptions of immune functions occur in many different cell types of the immune system, including macrophages [9-12,19]. Based on the possible effects of estrogenic and androgenic compounds on the immune system, the present study evaluated whether exposure of macrophages to common EDCs such as DHT, E2, and BPA modulate inflammatory biomarker production. These EDCs were selected for investigation due to literature available showing that they can be found in most water bodies impacted by human activity [6,37]. The study used a murine macrophage RAW264.7 cell line as a model for inflammatory responses. The inhibition of inflammation was assessed using NO and IL-6 as biomarkers of an inflammatory response. The results show that $5 \mu \mathrm{g} / \mathrm{mL}$ of DHT, E2, and BPA had no negative effect on RAW264.7 cell viability and were therefore not toxic.

The results further show that exposure of LPS-stimulated RAW264.7 cells to $5 \mu \mathrm{g} / \mathrm{mL}$ of DHT, E2, or BPA suppressed inflammatory biomarker secretion. The inhibition of inflammatory effects ischaracterized by significant decreases of NO and IL-6 secretions, compared with the positive control stimulated with $1 \mu \mathrm{g} / \mathrm{mL}$ LPS. These results indicate that DHT, E2, and BPA suppressed both NO and IL-6 secretion in stimulated RAW264.7 cells.

The actions of DHT through androgen receptors (ARs) are similar to those of testosterone, because DHT is a more biologically active form of testosterone. DHT is a derivative of testosterone synthesized from testosterone by enzymatic action of 5-reductase [7,8]. Its actions are also through ARs, whose expression has been detected in various immune cell types, such as macrophages $[19,20]$. The involvement of AR in the anti-inflammatory effects of DHT was confirmed by the results of combined DHT and flutamide treatment. The combined treatment of flutamide with DHT reversed the inhibition of inflammatory biomarker secretion by RAW264.7 cells. This is probably because flutamide is a selective antagonist of the AR [38]. A similar inhibition response in macrophage RAW264.7 cells culture might be induced by environmental androgenic pollutants. This is because androgens are common in sewage effluents and surface water bodies [6,37]. Therefore, these results suggest that anti-inflammatory activities of androgens, which are common in wastewater, can be assessed by the use of stimulated RAW264.7 cells culture. However, molecular mechanisms of androgen action on AR in macrophages require further studies.

Similarly, inhibitions of inflammatory biomarkers were evident upon treatment of stimulated RAW264.7 cells with E2 and BPA. The treatment of stimulated RAW264.7 cells with E2 and BPA suppressed inflammatory biomarkers by decreasing secretion of both NO and IL-6. The effects were more evident with E2 than BPA treatment. Both E2 and BPA can bind to estrogenic receptors (ERs), which are expressed in many immune cells including macrophages. The difference of E2 and BPA effects could be associated with differences in their affinity to ERs [39,40]. E2 is normally characterized by stronger estrogenic activities compared to BPA, which is characterized by weaker estrogenic activities [3]. Involvement of ERs in E2 and BPA inhibition of inflammatory biomarkers was confirmed by the results where LPS-activated RAW264.7 cells were exposed to combinations of E2 and BPA with tamoxifen. Tamoxifen is an ER antagonist [41]. Likewise, anti-inflammatory activities of estrogen might be induced by estrogenic pollutants. Estrogenic hormones have been frequently detected in sewage effluents and surface water bodies [35,37]. Hence, the findings of the present study suggest that anti-inflammatory activities of estrogenic pollutants can be evaluated by using stimulated RWA264.7 cell culture. Nevertheless, molecular mechanisms involving ER in macrophages may require further studies.

\section{Conclusions}

The results of the present study show that DHT, E2, and BPA, which are common EDCs in wastewater, can disrupt inflammatory response and hence immune function. The results show further that DHT, E2, and BPA can inhibit inflammatory mediator production in macrophages, 
partly through their respective steroid hormone receptors. These findings show that stimulated RAW264.7 macrophages may be a useful model for evaluation of inflammatory mediator inhibition activities of estrogenic and androgenic contaminants that are common in wastewater.

Author Contributions: V.W.M. performed experiments, analysed and interpreted data, and drafted the manuscript; E.J.P. designed the study, supervised and revised the manuscript.

Funding: This research received no external funding.

Conflicts of Interest: The authors declare no conflict of interest.

\section{References}

1. Kloas, W.; Lutz, I. Amphibians as model to study endocrine disrupters. J. Chromatogr. A 2006, 1130, 16-27. [CrossRef] [PubMed]

2. Zoeller, R.T.; Bergman, A.; Becher, G.; Bjerregaard, P.; Bornman, R.; Brandt, I.; Iguchi, T.; Jobling, S.; Kidd, A.K.; Kortenkamp, A.; et al. A path forward in the debate over health impacts of endocrine disrupting chemicals. Environ. Health 2014, 13, 118. [CrossRef] [PubMed]

3. Sun, Y.; Huang, H.; Sun, Y.; Wang, C.; Shi, X.L.; Hu, H.Y.; Fujie, K. Ecological risk of estrogenic endocrine disrupting chemicals in sewage plant effluent and reclaimed water. Environ. Pollut. 2013, 180, 339-344. [CrossRef] [PubMed]

4. Sun, Y.; Huang, H.; Sun, Y.; Wang, C.; Shi, X.; Hu, H.; Kameya, T.; Fujie, K. Occurrence of estrogenic endocrine disrupting chemicals concern in sewage plant effluent. Front. Environ. Sci. Eng. 2014, 8, 18-26. [CrossRef]

5. Bellet, V.; Hernandez-Raquet, G.; Dagnino, S.; Seree, L.; Pardon, P.; Bancon-Montiny, C.; Fenet, H.; Creusot, N.; Ait-Aïssa, S.; Cavailles, V.; et al. Occurrence of androgens in sewage treatment plants influents is associated with antagonist activities on other steroid receptors. Water Res. 2012, 46, 1912-1922. [CrossRef]

6. Liu, S.; Ying, G.G.; Zhao, J.L.; Chen, F.; Yang, B.; Zhou, L.J.; Lai, H.J. Trace analysis of 28 steroids in surface water, wastewater and sludge samples by rapid resolution liquid chromatography-electrospray ionization tandem mass spectrometry. J. Chromatogr. A 2011, 1218, 1367-1378. [CrossRef]

7. Pham, H.; Ziboh, V.A. $5 \alpha$-Reductase-catalyzed conversion of testosterone to dihydrotestosterone is increased in prostatic adenocarcinoma cells: Suppression by 15-lipoxygenase metabolites of gamma-linolenic and eicosapentaenoic acids. J. Steroid Biochem. Mol. Biol. 2002, 82, 393-400. [CrossRef]

8. Wu, Y.; Godoy, A.; Azzouni, F.; Wilton, J.H.; Ip, C.; Mohler, J.L. Prostate cancer cells differ in testosterone accumulation, dihydrotestosterone conversion, and androgen receptor signaling response to steroid $5 \alpha$-reductase inhibitors. Prostate 2013, 73, 1470-1482. [CrossRef]

9. Kuo, C.H.; Yang, S.N.; Kuo, P.L.; Hung, C.H. Immunomodulatory effects of environmental endocrine disrupting chemicals. Kaohsiung J. Med. Sci. 2012, 28, S37-S42. [CrossRef]

10. Bergman, A.; Heindel, J.J.; Kasten, T.; Kidd, K.A.; Jobling, S.; Neira, M.; Zoeller, R.T.; Becher, G.; Bjerregaard, P.; Bornman, R.; et al. The Impact of Endocrine Disruption a Consensus Statement on the State of the Science. Environ. Health Perspect. 2013, 121, A104-A106. [CrossRef]

11. Rogers, J.A.; Metz, L.; Yong, V.W. Endocrine disrupting chemicals and immune responses: A focus on bisphenol-A and its potential mechanisms. Mol. Immunol. 2013, 53, 421-430. [CrossRef] [PubMed]

12. Nakamura, K.; Kariyazono, H. Influence of endocrine-disrupting chemicals on the immune system. J. Health Sci. 2010, 56, 361-373. [CrossRef]

13. Schwartz, R.S. Immunodeficiency, immunosuppression, and susceptibility to neoplasms. JNCI Monogr. 2000, 28, 5-9. [CrossRef] [PubMed]

14. Marsland, A.L.; Bachen, E.A.; Cohen, S.; Rabin, B.; Manuck, S.B. Stress, immune reactivity and susceptibility to infectious disease. Physiol. Behav. 2002, 77, 711-716. [CrossRef]

15. Warrington, R.; Watson, W.; Kim, H.L.; Antonetti, F.R. An introduction to immunology and immunopathology. Allergy Asthma Clin. Immunol. 2011, 7, S1. [CrossRef] [PubMed]

16. Williams, A.E. Immunology: Mucosal and Body Surface Defences; John Wiley \& Sons Ltd.: Chichester, UK, 2011.

17. Carrillo, J.L.M.; García, F.P.C.; Coronado, O.G.; García, M.A.M.; Cordero, J.F.C. Physiology and Pathology of Innate Immune Response Against Pathogens. In Physiology and Pathology of Immunology; IntechOpen, 2017; Available online: https:/www.intechopen.com/books/physiology-and-pathology-of-immunology/ physiology-and-pathology-of-innate-immune-response-against-pathogens/ (accessed on 15 May 2019). 
18. Billack, B. Macrophage Activation: Role of Toll-like Receptors, Nitric Oxide, and Nuclear Factor Kappa B. Am. J. Pharm. Educ. 2006, 70, 102. [CrossRef] [PubMed]

19. Murphy, A.J.; Guyre, P.M.; Wira, C.R.; Pioli, P.A. Estradiol regulates expression of estrogen receptor ER $\alpha 46$ in human macrophages. PLoS ONE 2009, 4, e5539. [CrossRef]

20. Lai, J.J.; Lai, K.P.; Zeng, W.; Chuang, K.H.; Altuwaijri, S.; Chang, C. Androgen receptor influences on body defense system via modulation of innate and adaptive immune systems: Lessons from conditional AR knockout mice. Am. J. Pathol. 2012, 181, 1504-1512. [CrossRef]

21. Contrò, V.; Basile, J.R.; Proia, P. Sex steroid hormone receptors, their ligands, and nuclear and non-nuclear pathways. AIMS Mol. Sci. 2015, 2, 294-310. [CrossRef]

22. Campbell, L.; Emmerson, E.; Davies, F.; Gilliver, S.C.; Krust, A.; Chambon, P.; Ashcroft, G.S.; Hardman, M.J. Estrogen promotes cutaneous wound healing via estrogen receptor $\beta$ independent of its antiinflammatory activities. J. Exp. Med. 2010, 207, 1825-1833. [CrossRef]

23. Muraleedharan, V.; Jones, T.H. Testosterone and the metabolic syndrome. Ther. Adv. Endocrinol. Metab. 2010, 1, 207-223. [CrossRef] [PubMed]

24. Bianchi, V.E. The anti-inflammatory effects of testosterone. J. Endocr. Soc. 2018, 3, 91-107. [CrossRef] [PubMed]

25. Newton, K.; Dixit, V.M. Signaling in innate immunity and inflammation. Cold Spring Harb. Perspect. Biol. 2012, 4, a006049. [CrossRef] [PubMed]

26. Barnes, T.C.; Anderson, M.E.; Moots, R.J. The many faces of interleukin-6: The role of IL-6 in inflammation, vasculopathy, and fibrosis in systemic sclerosis. Int. J. Rheumatol. 2011. [CrossRef] [PubMed]

27. Mihara, M.; Hashizume, M.; Yoshida, H.; Suzuki, M.; Shiina, M. IL-6/IL-6 receptor system and its role in physiological and pathological conditions. Clin. Sci. 2012, 122, 143-159. [CrossRef] [PubMed]

28. Pool, E.J.; Magcwebeba, T.U. The screening of river water for immunotoxicity using an in vitro whole blood culture assay. Water Air Soil Pollut. 2009, 200, 25-31. [CrossRef]

29. Avdagić, N.; Zaćiragić, A.; Babić, N.; Hukić, M.; Šeremet, M.; Lepara, O.; Nakaš-Ićindić, E. Nitric oxide as a potential biomarker in inflammatory bowel disease. Bosn. J. Basic Med. Sci. 2013, 13, 5-9. [CrossRef] [PubMed]

30. Piva, S.J.; Tatsch, E.; De Carvalho JA, M.; Bochi, G.V.; Kober, H.; Duarte, T.; Duarte, M.M.M.; Manica da Cruz, I.B.; Moretto, M.B.; Moresco, R.N. Assessment of inflammatory and oxidative biomarkers in obesity and their associations with body mass index. Inflammation 2013, 36, 226-231. [CrossRef] [PubMed]

31. Kim, M. The effect of Prunella on anti-inflammatory activity in RAW264. 7 mouse macrophage cells. Food Nutr. Sci. 2012, 3, 1290.

32. Chen, C.L.; Zhang, D.D. Anti-inflammatory effects of 81 Chinese herb extracts and their correlation with the characteristics of traditional Chinese medicine. Evid. Based Complement. Altern. Med. 2014, 2014, 985176. [CrossRef] [PubMed]

33. Choi, H.S.; Seo, H.S.; Kim, S.R.; Choi, Y.K.; Shin, Y.C.; Ko, S.G. Anti-inflammatory and anti-proliferative effect of herbal medicines (APR) in RAW264. 7 cells. Mol. Med. Rep. 2014, 9, 1569-1574. [CrossRef] [PubMed]

34. Srisook, K.; Srisook, E.; Nachaiyo, W.; Chan-In, M.; Thongbai, J.; Wongyoo, K.; Chawsuanthong, S.; Wannasri, K.; Intasuwan, S.; Watcharanawee, K. Bioassay-guided isolation and mechanistic action of anti-inflammatory agents from Clerodendruminerme leaves. J. Ethnopharmacol. 2015, 165, 94-102. [CrossRef] [PubMed]

35. Faul, A.K.; Julies, E.; Pool, E.J. Steroid hormone concentrations and physiological toxicity of water from selected dams in Namibia. Afr. J. Aquat. Sci. 2014, 39, 1-10. [CrossRef]

36. Knez, J. Endocrine-disrupting chemicals and male reproductive health. Reprod. Biomed. Online 2013, 26, 440-448. [CrossRef] [PubMed]

37. Manickum, T.; John, W. Occurrence, fate and environmental risk assessment of endocrine disrupting compounds at the wastewater treatment works in Pietermaritzburg (South Africa). Sci. Total Environ. 2014, 468, 584-597. [CrossRef] [PubMed]

38. Brooke, G.N.; Gamble, S.C.; Hough, M.A.; Begum, S.; Dart, D.A.; Odontiadis, M.; Powell, S.M.; Fioretti, F.M.; Bryan, R.A.; Waxman, J.; et al. Antiandrogens act as selective androgen receptor modulators at the proteome level in prostate cancer cells. Mol. Cell. Proteom. 2015, 14, 1201-1216. [CrossRef] [PubMed]

39. Shanle, E.K.; $\mathrm{Xu}, \mathrm{W}$. Endocrine disrupting chemicals targeting estrogen receptor signaling: Identification and mechanisms of action. Chem. Res. Toxicol. 2010, 24, 6-19. [CrossRef] [PubMed] 
40. Kovats, S. Estrogen receptors regulate an inflammatory pathway of dendritic cell differentiation: Mechanisms and implications for immunity. Horm. Behav. 2012, 62, 254-262. [CrossRef] [PubMed]

41. An, K.C. Selective estrogen receptor modulators. Asian Spine J. 2016, 10, 787-791. [CrossRef]

(C) 2019 by the authors. Licensee MDPI, Basel, Switzerland. This article is an open access article distributed under the terms and conditions of the Creative Commons Attribution (CC BY) license (http://creativecommons.org/licenses/by/4.0/). 